\title{
Facile synthesis of fluorinated 2-aryl-5,7-bisalkyl pyrazolopyrimidines from arylalkynenitriles ${ }^{\dagger}$
}

\author{
V. V. V. N. S. Rama Rao, B. P. V. Lingaiah, G. Venkat Reddy, G. Ezikiel, R. Yadla, \\ and P. Shanthan Rao*
}

Fluoroorganic Division, Indian Institute of Chemical Technology, Hyderabad-500007, India E-mail: shanthanpp@yahoo.co.in

\begin{abstract}
Synthesis of pyrazolopyrimidines from fluorine-substituted arylalkynenitriles is described. Arylalkynenitriles 1a-d reacted with hydrazine to give 5-aryl-3-amino-2H-pyrazoles $\mathbf{2 a - 2 d}$. The condensation of aminopyrazoles with 1,3-dicarbonyl compounds furnished pyrazolopyrimidines 7a-h in good yield.
\end{abstract}

Keywords: Acetylenic nitriles, 1,3-dipolar cycloaddition, hydrazine, amino pyrazoles, 1,3dicarbonyl compounds, pyrazolopyrimidines

\section{Introduction}

Pyrazolopyrimidines are of considerable chemical and pharmacological importance as purine analogues, ${ }^{1,2}$ and have antitumor, antileukemic activities. Pyrazolo [1,5-a] pyrimidines have useful properties as antimetabolites in purine biochemical reactions. ${ }^{3-5}$ The pyrazole containing compounds have practical applications in the medicinal and agrochemical field and the biological activity ${ }^{6-8}$ of pyrazoles and its derivatives is well documented. The pyrazole ring has shown to be the basic moiety for a number of dyes, drugs and anesthetics. ${ }^{9,10}$ Amino and hydroxy substituted pyrazoles have been used as choline esterase inhibitors ${ }^{11}$. Our continued interest on the synthesis of fluorinated heterocycles, ${ }^{12,13}$ prompted us to synthesize fluorinated aminopyrazoles and pyrazolo pyrimidines by an elegant method of nucleophilic addition of acetylenic nitriles with hydrazine. The intermediate amine pyrazole is reacted with various 1,3dicarbonyl compounds, furnishing the pyrazolo pyrimidines. 


\section{Results and Discussion}

Acetylenic nitriles are known to undergo not only 1,3-dipolar cycloadditions but also nucleophilic addition with hydrazines ${ }^{14}$ to give aminopyrazoles or hydrazides. In the course of the chemistry of fluorinated alkynenitriles, we found that the addition of hydrazine to alkynenitrile $\mathbf{1}$ in ethanol at $0^{\circ} \mathrm{C}$ furnished cyclised product 3-amino-5-aryl pyrazole 2 as an exclusive product. Different fluorine substituted aryl alkynenitriles are utilized in the present investigation to obtain the cyclized pyrazoles. In contrast, 2,6-difluoro phenyl propynenitrile 1b gave the uncyclised hydrazide $\mathbf{3 b}$ intermediate as the major product, the cyclised aminopyrazole 2b being the minor component (Scheme 1).

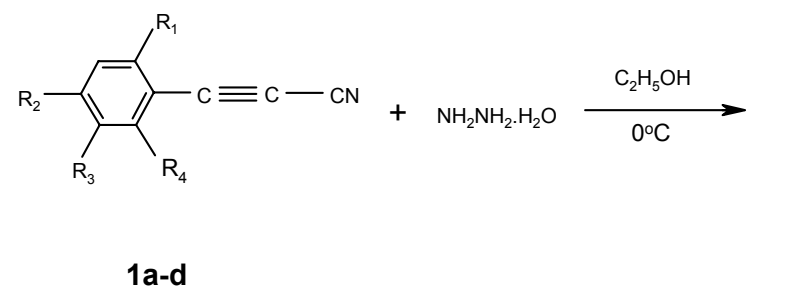

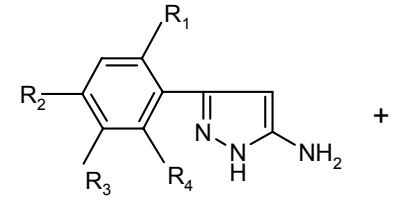

2

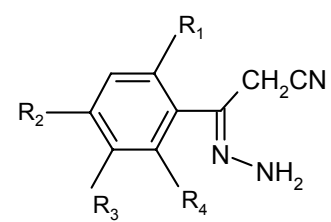

3
a) $\mathrm{R}_{1}=\mathrm{R}_{3}=\mathrm{R}_{4}=\mathrm{H}, \mathrm{R}_{2}=\mathrm{F}$
b) $\mathrm{R}_{1}=\mathrm{R}_{4}=\mathrm{F}, \mathrm{R}_{2}=\mathrm{R}_{3}=\mathrm{H}$
c) $\mathrm{R}_{1}=\mathrm{R}_{2}=\mathrm{R}_{3}=\mathrm{F}, \mathrm{R}_{4}=\mathrm{H}$
d) $\mathrm{R}_{1}=\mathrm{R}_{2}=\mathrm{R}_{3}=\mathrm{R}_{4}=\mathrm{H}$

\section{Scheme 1}

The IR spectra of amino pyrazoles 2a-d showed the absence of a peak in the region 2250$2260 \mathrm{~cm}^{-1}$ corresponding to the nitrile group and the presence of a broad absorption in the region 3410-3090 $\mathrm{cm}^{-1}$ assignable to amine function. The NMR spectra of 2a-d showed the characteristic signals at $\delta 2.9 \mathrm{ppm}$ for two protons $\left(-\mathrm{NH}_{2}\right)$ which is exchangable with $\mathrm{D}_{2} \mathrm{O}$ and a singlet for the pyrazole ring olefinic proton at $\delta 5.7 \mathrm{ppm}$. The mass spectra revealed a stable molecular ion and the characteristic loss of nitrogen by the fragmentation of pyrazole ring is observed in all the compounds 2a-d. Based on the spectral data, the compounds 2a-d are characterized as fluoro substituted derivatives of 5-aryl-2H-pyrazol-3-yl-amine.

The plausible mechanism for the formation of the arylamino pyrazoles 2a-d may be explained by the initial Michael type addition of the amino group onto the $\beta$-carbon of the alkynenitrile resulting in the alkenylhydrazide 4 intermediate. The latter further rearranges to give the $\beta$-cyanoalkylidene hydrazide $\mathbf{3}$, which conveniently undergoes intramolecular cycloaddition by the nucleophilic attack of the second amine onto the nitrile carbon to give the pyrazole imine, which upon aromatization leads to the amino pyrazole 2a-d as depicted in scheme- 2 . 
<smiles>[R]c1cc([R])c(C#C[C@@H](C#N)CN)c([R2])c1[R]</smiles>

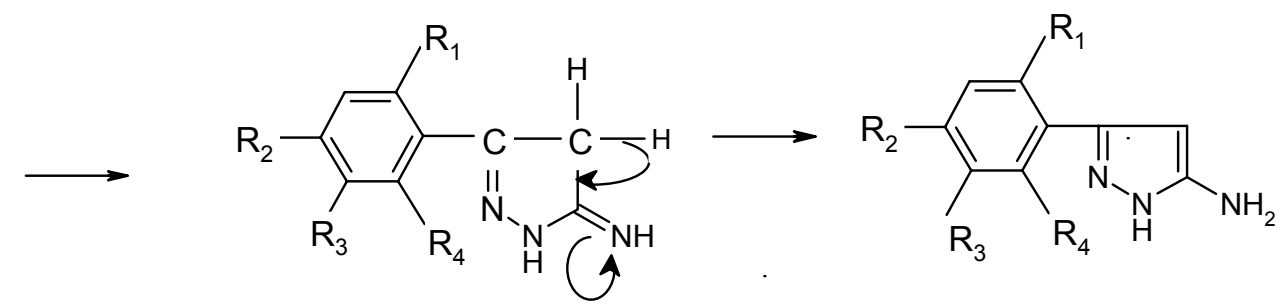

2

\section{Scheme 2}

The isolation of the intermediate hydrazide $\mathbf{3 b}$ in one of the reactions (for $\mathbf{1 b}$ ) along with the cyclized product confirms the mechanism showed above. This assumption is further confirmed when compound $\mathbf{3 b}$ furnished $\mathbf{2} \mathbf{b}$ in refluxing ethanol. The IR spectrum of $\mathbf{3 b}$ showed absorptions of $2240 \mathrm{~cm}^{-1}$ and $3320 \mathrm{~cm}^{-1}$ assignable to the nitrile and the amine, respectively. The NMR spectrum is in agreement with the assigned structure and revealed a singlet at $\delta 3.54 \mathrm{ppm}$ for two protons and a broad singlet at $\delta 5.47 \mathrm{ppm}$, which is exchangeable with $\mathrm{D}_{2} \mathrm{O}$, assigned to $-\mathrm{NH}_{2}$ protons. The mass spectrum revealed a molecular ion at $m / z 196$. The spectral data are in full agreement with the structure 3-(2,6-difluorophenyl)-3-hydrazinopropionitrile $\mathbf{3 b}$.

$3-(2,4,5-$ trifluorophenyl) propynenitrile 1c is a new compound and is prepared in good yield by microwave irradiation of [(2,4,5-trifluorobenzoyl)cyanomethylene $]$ triphenyl phosphorane 5c. The oxo-ylide 7 is obtained by the acylation of cyanomethylene triphenyl phosporane 5 with 2,4,5-trifluoro benzoyl chloride in dichloromethane (scheme 3). The other acetylenic nitriles are similarly obtained from the corresponding oxo-ylides. ${ }^{15}$

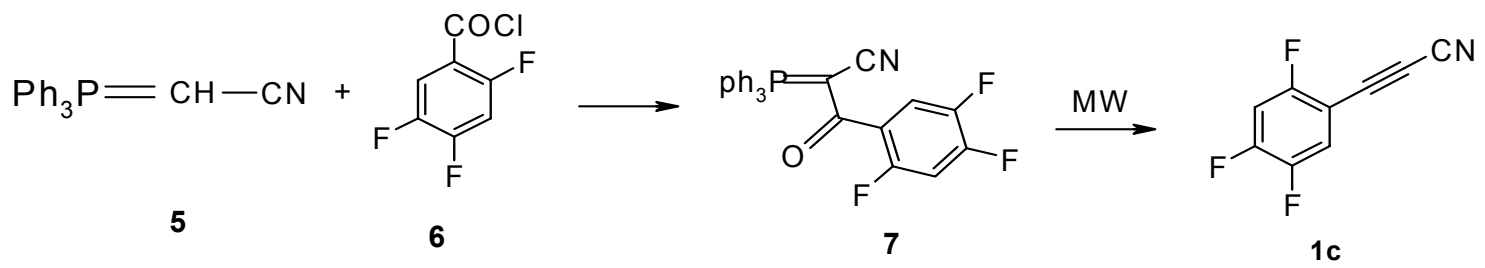

\section{Scheme 3}

The aminopyrazoles are active synthons and building blocks for many heterocyclic products. The presence of both primary and secondary amine functions in the same molecule is 
conveniently utilized in making hetero fused pyrazoles. The aminopyrazoles $\mathbf{2}$, when reacted with a 1,3-dicarbonyl compound $\mathbf{8}$ in refluxing ethanol, furnished the corresponding pyrazolopyrimidines $\mathbf{9}$. The reaction is expected to go by the initial formation of a mono Schiff's base which under the reaction conditions further cyclizes to furnish the stable pyrazolopyrimidine 9 in good yield (scheme 4).

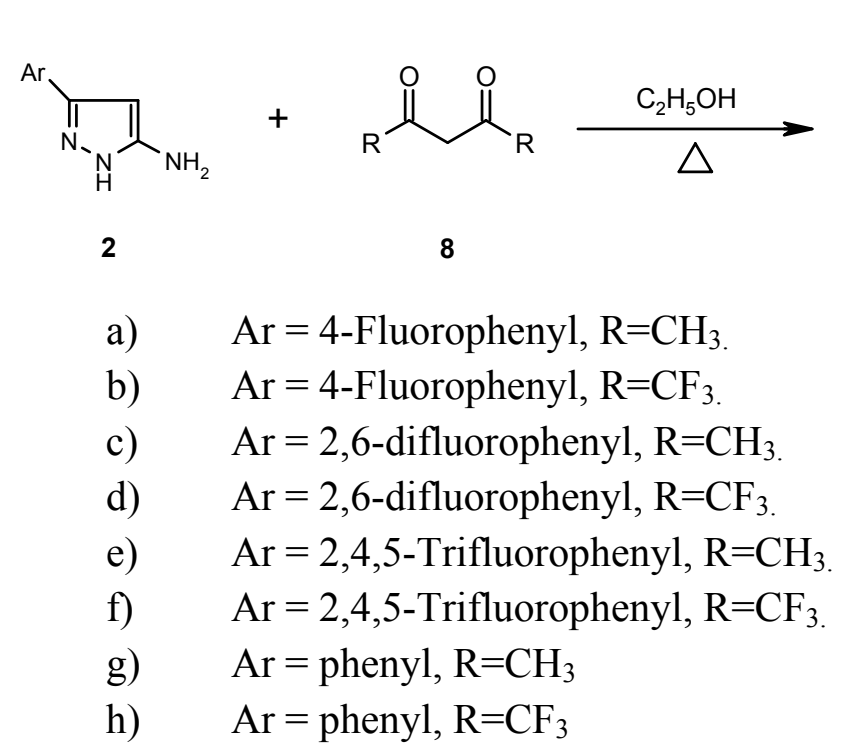

\section{Scheme 4}

The IR spectra of compounds 9a-d showed the disappearance of a broad peak due to -NH protons in the range $3100-3400 \mathrm{~cm}^{-1}$ and a carbonyl absorption is absent indicating that cyclization occurs. The NMR spectra showed the characteristic protons of pyrazole and pyrimidine rings at $\delta 6.48$ and $\delta 6.70 \mathrm{ppm}$, respectively. The mass spectra revealed stable the molecular ions and the loss of acetonitrile/trifluoro acetonitrile from molecular ion are observed in all the cases. The spectral data are in support of the assigned structure for the product 9 and is characterized as 2-aryl-5,7-bisalkyl pyrazolo[1,5-a] pyrimidine 9a, 9b.

We have, thus developed a straightforward route for the preparation of fluorinated aminopyrazoles and pyrazolopyrimidines from aryl substituted alkynenitriles, which are expected to be biologically important ring systems.

\section{Experimental Section}

General Procedures. Melting points were determined in open glass capillaries on a Fisher Johnes melting point apparatus and are uncorrected. IR spectra were recorded on FT-IR Schimadzu Perkin-Elmer 1310 infrared spectrophotometer. ${ }^{1} \mathrm{HNMR}(200 \mathrm{MHz})$ and ${ }^{13} \mathrm{C}$ NMR $(50 \mathrm{MHz})$ spectra were recorded on Varian Gemini spectrometer in $\mathrm{CDCl}_{3}$ solvent using TMS as 
internal standard. Mass spectra were recorded on a VG-micro mass $7070 \mathrm{H}$ instrument at $70 \mathrm{eV}$. Elemental analyses were carried out on EI Elemental Vario EL (Germany) apparatus.

General procedure for the preparation of 5-aryl-2H-pyrazole-3-yl-amine (2a-2d\& 3). Conjugated alkynenitrile 1 ( $2 \mathrm{mmol})$ was dissolved in dry ethanol $(2 \mathrm{ml})$, cooled to $-5^{\circ} \mathrm{C}$, and hydrazine hydrate solution $(2 \mathrm{mmol})$ was added and allowed to stir for $1 \mathrm{hr}$. After completion of reaction ethanol was removed and the residue was dissolved in $10 \mathrm{ml}$ of ethyl acetate, washed with water $(5 \mathrm{ml})$, separated the organic layer and dried over sodium sulfate. The ethyl acetate solution was adsorbed on silicagel (100-200 mesh) and purified by column chromatography. Hexane and 3\% ethyl acetate solvent mixture gave the corresponding amino pyrazole 2 .

5-(4-Fluorophenyl)-2H-pyrazole-3-yl-amine (2a). Yield 85\%. mp $154{ }^{\circ} \mathrm{C}$. IR (KBr): 34103090, 2911, $1514 \mathrm{~cm}^{-1} .{ }^{1} \mathrm{H}$ NMR (200 MHz, $\mathrm{CDCl}_{3}$ ): $\delta 2.97$ (br.s, 2H, $\mathrm{NH}_{2}$ ), 5.70 (s, 2H), 7.02 $\left(\mathrm{ddd}, 2 \mathrm{H},{ }^{3} \mathrm{~J}_{\mathrm{H}-\mathrm{H}}=8.8,{ }^{3} \mathrm{~J}_{\mathrm{H}-\mathrm{F}}=6.4,{ }^{4} \mathrm{~J}_{\mathrm{H}-\mathrm{H}}=2.2 \mathrm{~Hz}\right), 7.61\left(\mathrm{ddd}, 2 \mathrm{H},{ }^{3} \mathrm{~J}_{\mathrm{H}-\mathrm{H}}=8.8,{ }^{4} \mathrm{~J}_{\mathrm{H}-\mathrm{F}}=5.3,{ }^{4} \mathrm{~J}_{\mathrm{H}-\mathrm{H}}=2.1 \mathrm{~Hz}\right)$. EIMS $m / z$ (relative intensity) $177\left(\mathrm{M}^{+}, 100\right), 176(12), 149$ (8), 148 (75). Anal. Calcd. for $\mathrm{C}_{8} \mathrm{H}_{8} \mathrm{FN}_{3}$ C, 61.01; H, 4.55; N, 23.72. Found: C, 60.99; H, 4.56; N, 23.71\%.

5-(2,6-Difluorophenyl)-2H-pyrazole-3-yl-amine (2b). Yield 8.5\%. mp $128{ }^{\circ} \mathrm{C}$. IR (KBr): 34093111, 2910, $1525 \mathrm{~cm}^{-1} .{ }^{1} \mathrm{H}$ NMR $\left(200 \mathrm{MHz}, \mathrm{CDCl}_{3}\right): \delta 5.41$ (s, 1H), 6.26 (br.s, 2H), 7.23-7.42 (m, 3H). EIMS $m / z$ (relative intensity) $195\left(\mathrm{M}^{+}, 80\right), 178$ (100). Anal. Calcd. for $\mathrm{C}_{9} \mathrm{H}_{7} \mathrm{~F}_{2} \mathrm{~N}_{3} \mathrm{C}$, 55.39; H, 3.61; N, 25.53. Found: C, 55.73; H, 3.87; N, 25.70\%.

5-(2,4,5-Trifluorophenyl)-2H-pyrazole-3-ylamine (2c). Yield 79\%. mp $132{ }^{\circ} \mathrm{C}$. IR ( $\left.\mathrm{KBr}\right)$ : 3406-3100, 2911, $1514 \mathrm{~cm}^{-1} .{ }^{1} \mathrm{H}$ NMR (200 MHz, $\mathrm{CDCl}_{3}$ ): $\delta 3.77$ (br.s, 2H), 5.92 (s, 1H), 7.02 $(\mathrm{m}, 1 \mathrm{H}), 7.43(\mathrm{~m}, 1 \mathrm{H})$. EIMS $\mathrm{m} / z$ (relative intensity) $213\left(\mathrm{M}^{+}, 60\right), 184(45), 156(100)$. Anal. Calcd. for $\mathrm{C}_{9} \mathrm{H}_{6} \mathrm{~F}_{3} \mathrm{~N}_{3}$ C, 50.71; H, 2.84; N, 19.71. Found: C, 50.73; H, 2.87; N, 19.70\%.

5-Phenyl-2H-pyrazole-3-ylamine (2d). Yield 76\%.mp $145{ }^{\circ} \mathrm{C}$. IR (KBr): 3380-3100, 2928, $1369 \mathrm{~cm}^{-1} .{ }^{1} \mathrm{H}$ NMR $\left(200 \mathrm{MHz}, \mathrm{CDCl}_{3}\right.$ ): $\delta 2.92$ (br.s, 2H), 5.92 (s, 1H), 7.45 (s, 3H), 7.74 (m, $2 \mathrm{H})$. EIMS $m / z$ (relative intensity) $159\left(\mathrm{M}^{+}, 35\right), 131$ (100). Anal. Calcd. for $\mathrm{C}_{9} \mathrm{H}_{9} \mathrm{~N}_{3} \mathrm{C}, 67.91$; H, 5.70; N, 26.90. Found: C, 67.92; H, 5.73; N, 26.88\%.

3-(2,6-Difluorophenyl)-3-hydrazinopropionitrile (3). Yield 81\%. mp $126{ }^{\circ} \mathrm{C}$. IR (KBr): 3210 , 2925, $2340 \mathrm{~cm}^{-1} .{ }^{1} \mathrm{H}$ NMR (200 MHz, $\mathrm{CDCl}_{3}$ ): $\delta 3.54$ (s, 2H), 5.47 (br.s, 2H), 7.04 (m, 2H), 7.46 (m, 1H). EIMS $m / z$ (relative intensity) $195\left(\mathrm{M}^{+}, 25\right), 155$ (100). Anal. Calcd. for $\mathrm{C}_{9} \mathrm{H}_{7} \mathrm{~F}_{2} \mathrm{~N}_{3} \mathrm{C}$, 55.39; H, 3.62; N, 21.83. Found: C, 55.41; H, 3.65; N, 21.52\%.

General procedure for the preperation of 3-(2,4,5-trifluorophenyl)propynenitrile (1c). The [(2,4,5-trifluorobenzoyl)cyanomethylene]triphenylphosporane 7 was taken in a sealed tube and subjected to microwave irradiation for 5.5 mins. The ylide 7 was decomposed at 600 Watts microwave power. The dark brown reaction mixture was cooled to room temperature, and was dissolved in dichloromethane $(10 \mathrm{ml})$ and purified by column chromatography using silicagel (100-200 mesh).

2,4,5-Trifluorophenylpropynenitrile (1c). Yield 84\%. mp $38{ }^{\circ} \mathrm{C}$. IR (KBr): 3040, 2919, 2271,2185, 1502, 1397, $1183 \mathrm{~cm}^{-1} .{ }^{1} \mathrm{H}$ NMR (200 MHz, $\left.\mathrm{CDCl}_{3}\right): \delta 6.99-7.14(\mathrm{~m}, 1 \mathrm{H}), 7.35-7.47$ (m, 1H). EIMS $m / z$ (relative intensity) $181\left(\mathrm{M}^{+}, 100\right), 130(7), 112(6), 75(8), 55(8), 41(18)$. Anal. Calcd. for $\mathrm{C}_{9} \mathrm{H}_{2} \mathrm{~F}_{3} \mathrm{~N}$ C, 59.68; H, 1.11; N, 7.73. Found: C, 59.41; H, 1.65; N, 7.52\%. 
General procedure for the preparation of 2-aryl-5, 7-dialkyl-pyrazolo[1,5-a]pyrimidines 9a-9h. 3-Amino pyrazole (1 mmol) was dissolved in ethanol $(2 \mathrm{ml})$ and added to an ethanolic solution of a symmetrical 1,3-diketone $(1 \mathrm{mmol})$ at once and allowed to reflux for $3 \mathrm{hr}$. The solvent was removed from the reaction mixture and the crude material was purified by column chromatography.

2-(4-Fluorophenyl)-5,7-dimethyl-pyrazolo[1,5-a]pyrimidine (9a). Yield 81\%. mp $69{ }^{\circ} \mathrm{C}$. IR (KBr): 2923, 1607, 1463, 1266, $1150 \mathrm{~cm}^{-1} .{ }^{1} \mathrm{H}$ NMR (200 MHz, $\left.\mathrm{CDCl}_{3}\right): \delta 2.48(\mathrm{~s}, 3 \mathrm{H}), 2.71(\mathrm{~s}$, $3 \mathrm{H}), 6.48(\mathrm{~s}, 1 \mathrm{H}), 6.71(\mathrm{~s}, 1 \mathrm{H}), 7.02-7.11(\mathrm{~m}, 2 \mathrm{H}), 7.88-7.95(\mathrm{~m}, 2 \mathrm{H})$. EIMS m/z (relative intensity) $241\left(\mathrm{M}^{+}, 60\right), 191$ (11), 149 (17), 105 (35), 91(55), 57(100). Anal. Calcd. for $\mathrm{C}_{14} \mathrm{H}_{12} \mathrm{FN}_{3}$ C, 69.70; H, 5.01; N, 17.42. Found: C, 69.72; H, 5.04; N, 17.41\%.

2-(4-Fluorophenyl)-5,7-bis-trifluoromethyl-pyrazolo[1,5-a]pyrimidine (9b). Yield 77\%. mp $54{ }^{\circ} \mathrm{C}$. IR (KBr): 3041, 2923, $1598 \mathrm{~cm}^{-1} .{ }^{1} \mathrm{H}$ NMR (200 MHz, $\left.\mathrm{CDCl}_{3}\right): \delta$ 7.09-7.13 (m, 2H), 7.19 (s, 1H), 7.36 (s, 1H), 7.96-8.02 (m, 2H). EIMS m/z (relative intensity) $349\left(\mathrm{M}^{+}, 90\right), 280$ (65). Anal. Calcd. for $\mathrm{C}_{14} \mathrm{H}_{6} \mathrm{~F}_{7} \mathrm{~N}_{3}$ C, 48.15; H, 1.73; N, 12.03. Found: C, 48.15; H, 1.76; N, 12.04\%.

2-(2,6-Difluorophenyl)-5,7-dimethyl-pyrazolo[1,5-a]pyrimidine (9c). Yield 83\%. mp $66{ }^{\circ} \mathrm{C}$. IR (KBr): 2933, 1617, 1463, 1265, $1155 \mathrm{~cm}^{-1} .{ }^{1} \mathrm{H}$ NMR $\left(200 \mathrm{MHz}, \mathrm{CDCl}_{3}\right): \delta 2.35(\mathrm{~s}, 3 \mathrm{H}), 2.74$ $(\mathrm{s}, 3 \mathrm{H}), 6.27(\mathrm{~s}, 1 \mathrm{H}), 6.95(\mathrm{~s}, 1 \mathrm{H}), 7.05-7.10(\mathrm{~m}, 2 \mathrm{H}), 7.36-7.42(\mathrm{~m}, 1 \mathrm{H})$. EIMS m/z (relative intensity) $259\left(\mathrm{M}^{+}, 55\right), 244$ (100). Anal. Calcd. for $\mathrm{C}_{14} \mathrm{H}_{11} \mathrm{~F}_{2} \mathrm{~N}_{3}$ C, 64.86; H, 4.28; N, 16.21. Found: C, 64.72; H, 4.04; N, 16.41\%.

2-(2,6-Difluorophenyl)-5,7-bistrifluoromethyl-pyrazolo[1,5-a]pyrimidine (9d). Yield 78\%. mp $50{ }^{\circ} \mathrm{C}$. IR (KBr): 3031, 2925, $1600 \mathrm{~cm}^{-1} .{ }^{1} \mathrm{H}$ NMR (200 MHz, $\left.\mathrm{CDCl}_{3}\right): \delta$ 7.05-7.12 (m, 3H), 7.34-7.40 (s, 1H), 7.58 (s, 1H). EIMS m/z (relative intensity) $367\left(\mathrm{M}^{+}, 80\right), 298$ (70). Anal. Calcd. for $\mathrm{C}_{14} \mathrm{H}_{5} \mathrm{~F}_{8} \mathrm{~N}_{3}$ C, 45.79; H, 1.37; N, 11.44. Found: C, 45.15; H, 1.76; N, 11.04\%.

2-(2,4,5-Trifluorophenyl)-5,7-dimethyl-pyrazolo[1,5-a]pyrimidine(9e). Yield 86\%. mp $60{ }^{\circ} \mathrm{C}$. IR (KBr): 2933, 1617, 1463, 1265, $1155 \mathrm{~cm}^{-1} .{ }^{1} \mathrm{H}$ NMR (200 MHz, $\mathrm{CDCl}_{3}$ ): $\delta 2.35$ (s, 3H), 2.73 $(\mathrm{s}, 3 \mathrm{H}), 6.27$ (s, 1H), $6.57(\mathrm{~s}, 1 \mathrm{H}), 7.21-7.132(\mathrm{~m}, 2 \mathrm{H})$. EIMS m/z (relative intensity) $277\left(\mathrm{M}^{+}\right.$, 75), 262 (10). Anal. Calcd. for $\mathrm{C}_{14} \mathrm{H}_{10} \mathrm{~F}_{3} \mathrm{~N}_{3}$ C, 60.65; H, 3.64; N, 15.16. Found: C, 60.72; H, $3.04 ; \mathrm{N}, 15.41 \%$.

2-(2,4,5-Trifluorophenyl)-5,7-bistrifluoromethyl-pyrazolo[1,5-a]pyrimidine (9f). Yield 77\%. mp $49{ }^{\circ} \mathrm{C}$. IR (KBr): 30412 2934, $1580 \mathrm{~cm}^{-1} .{ }^{1} \mathrm{H}$ NMR (200 MHz, $\left.\mathrm{CDCl}_{3}\right): \delta 6.70(\mathrm{~s}, 1 \mathrm{H})$, 7.15-7.25 (m, 2H), 7.58 (s, 1H). EIMS m/z (relative intensity) $385\left(\mathrm{M}^{+}, 65\right), 316$ (65). Anal. Calcd. for $\mathrm{C}_{14} \mathrm{H}_{4} \mathrm{~F}_{9} \mathrm{~N}_{3}$ C, 43.65; H, 1.05; N, 10.91. Found: C, 43.15; H, 1.76; N, 10.04\%.

\section{Acknowledgements}

The authors are thankful to Dr. J. S. Yadav, Director, IICT, Hyderabad and to Mr. S.Narayan Reddy, HOD, Fluoroorganic division for their constant encouragement. VVVNSRR is thankful to CSIR, New Delhi for the award of senior research fellowship. 


\section{References and Footnotes}

1. Bendich, A..; Russell, P. J. Jr.; Fox, J. J. J. Am. Chem. Soc. 1954, 76, 6073.

2. Kabayasahi, S. J. Pharm. Bull. 1973, 21, 941.

3. Alexander, J. O.; Wheeler, G. R.; Hill, P. D.; Morris, M. P. Biochem. Pharmacol. 1966, 15, 881.

4. Elion,G. B.; Callahan, S.; Nathan, H.; Bieher, S.; Rundles, R. W.; Hitchings, G. H. Biochem. Pharmacol. 1963, 12, 85.

5. Earl, R. A.; Pugmire, R. J.; Revanker, G. R.; Townsend, L. B. J.Org.Chem. 1975, 40, 1822.

6. Novinson, T.; Dimmit, R. M. K.; Simon, I.N.; Robins, R. K.; Brien, D. E. O. J. Med. Chem. 1974, 17, 645.

7. Krikpatrick, W. E.; Okabe, T.; Hillyard, I. W.; Robins, R. K.; Dren, A. T.; Novinson, T. J. Med. Chem. 1977, 20, 386.

8. Elagamy, A. A.; El-Taweel, F. M. A.; Amer, F. A.; Zoorob, H. H. Arch. Pharm. (Weinhei) 1987, 320, 246.

9. (a) Kost, A. N.; Grandberg, I. I. In Advances in Heterocyclic Chemistry Katritzky, A.R. Ed. Academic Press: New York, 1996, p 347. (b) Nihset, H. B. J. Chem. Soc. 1938, 1568.

10. (a) Raiziss, G. W.; Clemence, L. W.; Friefelder, M. J. Am. Chem. Soc. 1941, 63, 2739. (b) Guarneri, M. Bull. Chim. Far. 1960, 99, 259. compounds-Pyrazolones

11. (a) Olah, G. A.; Iyer, P. S.; Prakash, S. Synthesis, 1982, 523. (b) Weisberger, A. "The Chemistry of Heterocyclic Pyrazolidones and derivatives", New York, 1964; Vol. 20, pp $1-539$.

12. Rama Rao, V. V. V. N. S.; Reddy, G. V.; Maitraie, D.; Ravikanth, S.; Yadla, R.; Narsaiah, B.; Shanthan Rao, P. Tetrahedron, 2004, 60, 12231.

13. Rama Rao, V. V. V. N. S.; Reddy, G. V.; Yadla, R.; Narsaiah, B.; Shanthan Rao, P. Arkivoc, 2005, (iii), 211.

14. (a) Viehe, H. G. In Chemistry of Acetylenes Marcel Dekker, New York, 1969; p 462. (b) Martin, M. R. Heterocycles, 1989, 29, 967.

15. Rama Rao, V. V. V. N. S.; Ravikanth, S.; Reddy, G. V.; Maitraie, D.; Yadla, R.; Shanthan Rao, O. Synth. Commun. 2003, 33, 1523. 